\title{
Common starling Sturnus vulgaris expansion in South Africa
}

Author(s):

Ivanova IM and Symes CT
Journal editor:

Pete Laver

Manuscript editor:

Les Underhill

Received: January 25, 2018; Accepted: September 11, 2018; Published: September 11, 2018

\section{Citation: Ivanova IM and Symes CT. 2018. Common starling Sturnus vulgaris expansion in South Africa. Biodiversity Observations 9.9:1-6}

Journal: https://journals.uct.ac.za/index.php/BO/

Manuscript: https://journals.uct.ac.za/index.php/BO/article/view/502

PDF: https://journals.uct.ac.za/index.php/BO/article/view/502/557

HTML: http:/ / thebdi.org/blog/2018/09/11/common-starling-range-expansion
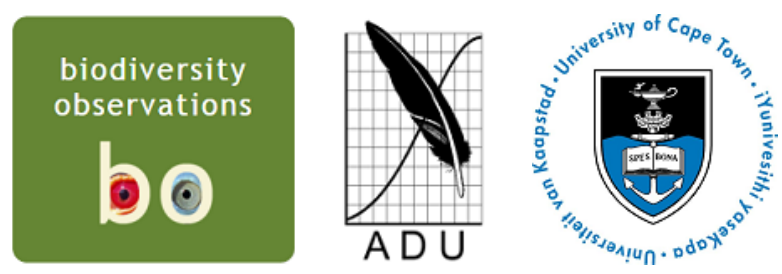

Biodiversity Observations is an open access electronic journal published by the Animal Demography Unit at the University of Cape Town, available at https://journals.uct.ac.za/index.php/BO/

The scope of Biodiversity Observations includes papers describing observations about biodiversity in general, including animals, plants, algae and fungi. This includes observations of behaviour, breeding and flowering patterns, distributions and range extensions, foraging, food, movement, measurements, habitat and colouration/plumage variations. Biotic interactions such as pollination, fruit dispersal, herbivory and predation fall within the scope, as well as the use of indigenous and exotic species by humans. Observations of naturalised plants and animals will also be considered. Biodiversity

Observations will also publish a variety of other interesting or relevant biodiversity material: reports of projects and conferences, annotated checklists for a site or region, specialist bibliographies, book reviews and any other appropriate material. Further details and guidelines to authors are on the journal website (https://journals.uct.ac.za/index.php/BO/). 


\section{Common starling Sturnus vulgaris expansion in South Africa}

lelyzaveta M Ivanova* School of Animal, Plant and Environmental Sciences, University of the Witwatersrand, Private Bag 3, Wits 2050, South Africa

Craig T Symes School of Animal, Plant and Environmental Sciences, University of the Witwatersrand, Private Bag 3, Wits 2050, South Africa

The Common Starling Sturnus vulgaris is a medium-sized granivorous and frugivorous bird (Craig 2005), with a native range across large parts of Europe and western Asia. It was introduced to Cape Town in 1899, colonising the Cape region during the early 20th century (Winterbottom \& Liversidge 1954). Since then, the species has continued to systematically extend its range into South Africa (Craig 2005). Using the available data in SABAP2, collected over the last 10 years (July 2007 - June 2017), we present a summary of the species presence in South Africa and its progressive expansion into the Gauteng Province specifically.

The number of pentads (5'x5' geographical grids used in SABAP2) reporting the presence of the Common Starling in the country appears to be relatively stable over the period assessed: 739 pentads in the 2016/17 period compared to 677 pentads in 2008/09, with a peak in 2009/10 and 2010/11 (Table 1). A notable exception to this is the period 2007/08, where only 383 pentads reported the Common Starling (Table 1, Figure 1). This appears to be due to the low sampling effort at that stage, given the high percentage of all sampled pentads that this figure represented for that period (Table 1, bracketed figure). Despite a stable numerical pentad representation, the species appears to still be expanding some of its range, as shown by the large numbers of previously unoccupied pentads reporting the Starling over time (Table 1). The overall proportion of pentads reporting the Starling shows a steady decline over the period, which would likely be attributed to increases in the overall SABAP sampling effort (of Starling absent pentads) outpacing the species range expansion. Across its range, the Common Starling appears to have a relatively consistent abundance over time (as represented by the Starling's reporting rate, Table 1 ).

The slight declines in the species range and abundance over the 10 years indicate that the presence of the species in an area does not necessarily result in long-term persistence. A similar decline is observed for the Starling in the United States, following a very rapid period of initial colonisation (Sauer et al. 2008). The expansion of the Starling's range appears to be mitigated numerically by its contraction elsewhere in the country, resulting in the stable numbers of Starling-reporting pentads seen in Table 1. As such, the colonising behaviour of the Common Starling in South Africa appears to be one of venturing into new territory, with a lag period of decline in less suitable areas where it may not be able to persist. A possible explanation of the high expansion rate is the general tendency to move along pathways of lower resistance, such as lower elevation terrain that is preferably under cropland or pasture (with the contrary

Biodiversity Observations is an open access electronic journal published by the Animal Demography Unit at the University of Cape Town, available at https://journals.uct.ac.za/index.php/BO/. A permanent link for an online version of this manuscript can be found at https://journals.uct.ac.za/index.php/BO/article/view/502, which includes the PDF: https://journals.uct.ac.za/index.php/BO/article/view/502/557. An HTML version can be found at http:/ / thebdi.org/blog/2018/09/11/common-starling-range-expansion.

Journal editor: Pete Laver; Manuscript editor: Les Underhill; ${ }^{*}$ Corresponding author: ielyzaveta.ivanova@gmail.com

Received: January 25, 2018; Accepted: September 11, 2018; Published: September 11, 2018

Recommended citation: Ivanova IM and Symes CT. 2018. Common starling Sturnus vulgaris expansion in South Africa. Biodiversity Observations 9.9:1-6

Manuscript subject: Avian ranges 


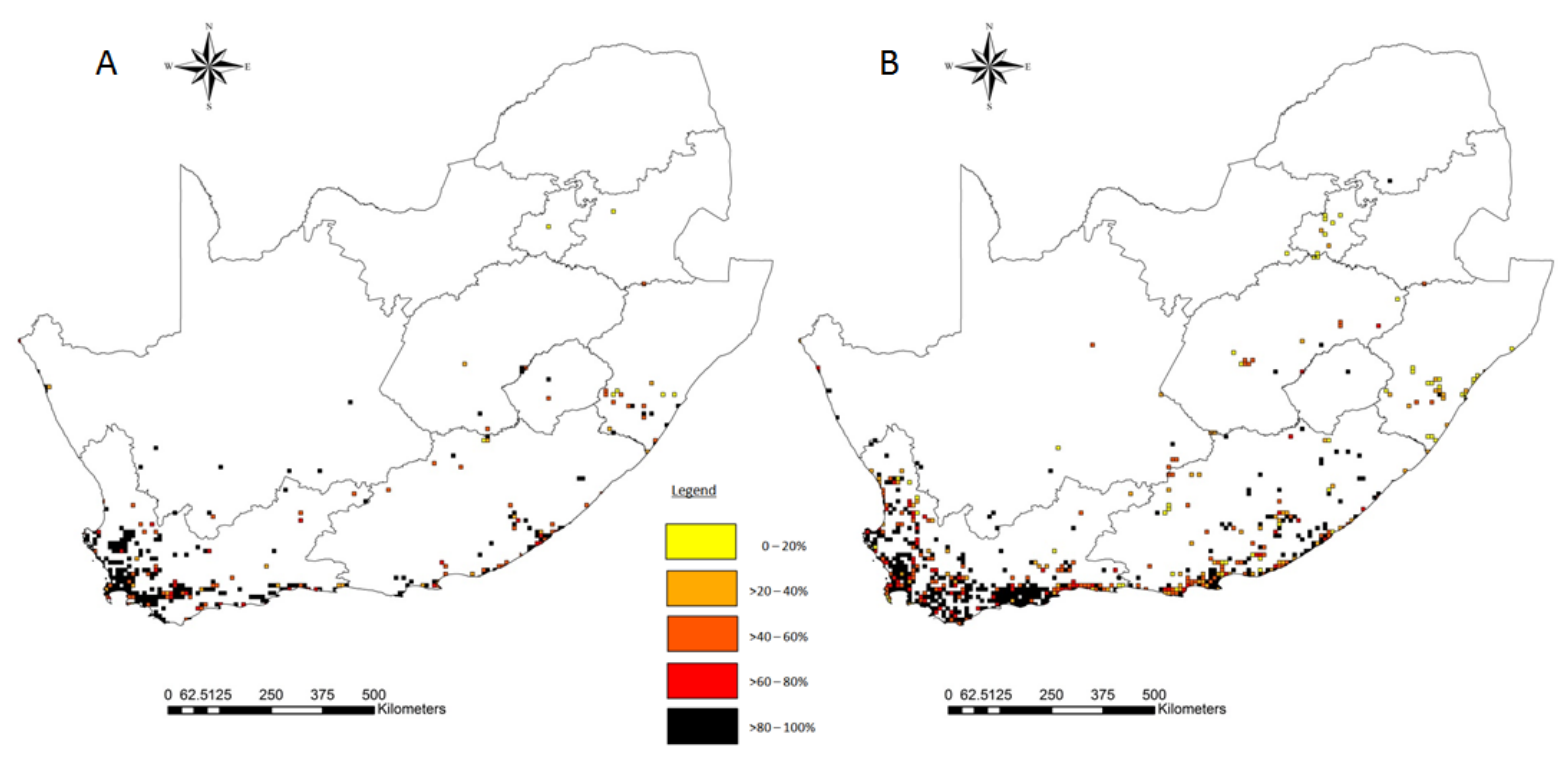

Figure 1: Reporting rates of the Common Starling across pentads $\left(5^{\prime} X 5^{\prime}\right.$ geographical grids) in South Africa, in July 2007 - June 2008 (A) and July 2016 - June 2017 (B). Different colours denote reporting rates, presented as percentage of all record cards completed in each given pentad.

causing a greatly slowed expansion, such as in the Iberian Peninsula, Ferrer et al. 1991).

\section{Common Starling in Gauteng}

In Gauteng, the Common Starling first made an appearance in 1986 (Boucher 2018), but consistent reporting of the species in the region did not begin until the early 21st century. A recent arrival, the Starling is already making steady range gains, being reported in "new" Gauteng pentads in each data period (Table 2). With the increasing number of pentads reporting the Starling, the average reporting rate for the species across the province is showing an obvious rise (Table 2). Such an expansion pattern resembles the initial phases of the Starling's colonisation of the country at large, as discussed previously - quick gains in range.

The reporting rate for the Starling across Gauteng as a whole averages only $0.18 \%$ for the 10 years, reflecting the novel status that the species still holds in the province. The increase in Starling reporting rates is not statistically significant at this stage, despite their apparent growth (ANOVA single factor test; $F(9,2647)=1.627, p=0.102$ ). A likely explanation of this is the very high variability observed in the annual averages (Table 2 ).

From the growing reporting rates and increasing variability, it can be noted that the lag period of decline following rapid territory colonisation seen for the Common Starling in South Africa as a whole is not yet identified in Gauteng, but may follow on in the years to come.

Assessing a variety of land uses found in Gauteng, the Starling's presence is consistently below $1 \%$ throughout (when pentads are averaged by share of land-use type), not being reported at all in pentads with agriculture comprising over $60 \%$ of land use (Table 3). This finding supports the attribution of the traditionally farmland-inhabiting Common Starling's decline in Europe to the intensification of agricultural areas (Donald et al. 2001).

While sampling effort has increased over the years of the atlas, as awareness of and interest in the project grows, the range expansion of the Common Startling in Gauteng appears to not simply be a function of that effort - rather, we believe it reflects an actual increase in the number of pentads in which it occurs, which is supported by the growing percentage of sampled pentads reporting the species (Table 2). 
Table 1: Range expansion and abundance of the Common Starling in South Africa, for July-June annual periods in 10 years of SABAP2 sampling (July 2007 - June 2017).

\begin{tabular}{cccc}
\hline Year period $^{\mathrm{a}}$ & Pentads $^{\mathrm{b}}$ & New $^{\mathrm{c}}$ & Reporting rate $^{\mathrm{d}}$ \\
\hline $2007 / 08$ & $383(19.8)$ & 383 & $50 \pm 45$ \\
$2008 / 09$ & $677(15.9)$ & 423 & $52 \pm 45$ \\
$2009 / 10$ & $864(16.6)$ & 334 & $52 \pm 43$ \\
$2010 / 11$ & $865(15.9)$ & 251 & $53 \pm 44$ \\
$2011 / 12$ & $843(15.6)$ & 191 & $52 \pm 43$ \\
$2012 / 13$ & $759(14.8)$ & 124 & $51 \pm 44$ \\
$2013 / 14$ & $636(12.2)$ & 83 & $47 \pm 44$ \\
$2014 / 15$ & $659(12.0)$ & 82 & $48 \pm 44$ \\
$2015 / 16$ & $804(13.4)$ & 106 & $46 \pm 43$ \\
$2016 / 17$ & $736(12.2)$ & 72 & $45 \pm 43$ \\
\hline \multicolumn{4}{c}{ a July - June) } \\
${ }^{\mathrm{b}}$ Number of pentads with Starlings (as \% of sampled pentads) \\
${ }^{\mathrm{c} N u m b e r}$ of new pentads with Starlings \\
${ }^{\mathrm{d}}$ Reporting rate across Starling-reporting pentads (mean \% \pm SD)
\end{tabular}

\section{General conclusions}

In South Africa, the Common Starling appears to be following an shifting distribution pattern, as it expands into new territory and establishes its presence. From the pattern of expansion, it is possible to speculate a future Starling distribution that spans the entire country and subregion, albeit an uncertain long-term persistence there. Whether it is able to colonise into more "unfavourable" regions (such as the dry Northern Cape Province) remains to be established. The species is expected to be most abundant in areas where agriculture is a prominent, but not dominant, land use (Table 3), indicating an avoidance for what is likely to be intensified farmland (cf. Donald et al. 2001). However, more work is needed to disentangle the potential impact of sampling effort on the resultant reporting rate of the Starling.

With regards to Gauteng, the future of the Common Starling is challenging to determine, as the observations are of a trend arguably in its initial phases. However, some extrapolations can be made. The open grassland of pre-settlement Gauteng would have been prohibitive to Common Starling colonisation, but the conditions for colonisation have since changed. Its diet of insects and fruits is well-suited to the now-afforested expanses of Gauteng cities (Schäffler \& Swilling 2012), as is its preference of cavities for nesting. If its preference for areas with intermediate levels of agriculture, settlement, and land transformation persist, the species will continue increasing in both range and abundance across the province (which features a large proportion of relatively densely settled and transformed spaces). Therefore, it is likely that the species increase in Gauteng will become significant over time.

The Common Starling has been described as having the potential to disrupt natural processes such as seed dispersal (Richardson et al. 1996); however, not much work has been published on these impacts in the Cape region. The Starling is also thought to be able to displace cavity-nesting birds in southern Africa through nesting competition, as it does with the Olive Woodpecker Mesopicos griseocephalus (van der Merwe 1984). On the other hand, in the introduced range around New York City, there is little evidence to attribute a decline in cavitynesting native species to competition with the Starling (Koenig 2003). Therefore, the impact of Starling on other bird species in Gauteng (many themselves occurring in increased abundance due to anthropogenic change) is difficult to predict. A further consideration is that alien birds are known to form positive as well as negative interactions with not only native birds, but also 
Table 2: Range expansion and abundance of Common Starling in Gauteng, for July-June annual periods in 10 years of SABAP2 sampling (July 2007 - June 2017).

\begin{tabular}{cccc}
\hline Year period $^{\mathrm{a}}$ & Pentads $^{\mathrm{b}}$ & New $^{\mathrm{c}}$ & Reporting rate $^{\mathrm{d}}$ \\
\hline $2007 / 08$ & $1(0.5)$ & 1 & $0.02 \pm 0.30$ \\
$2008 / 09$ & $4(1.5)$ & 3 & $0.06 \pm 0.50$ \\
$2009 / 10$ & $1(0.4)$ & 1 & $0.05 \pm 0.86$ \\
$2010 / 11$ & $1(0.4)$ & 1 & $0.07 \pm 1.20$ \\
$2011 / 12$ & $4(1.5)$ & 2 & $0.39 \pm 3.82$ \\
$2012 / 13$ & $4(1.6)$ & 1 & $0.05 \pm 0.48$ \\
$2013 / 14$ & $4(1.4)$ & 3 & $0.18 \pm 1.69$ \\
$2014 / 15$ & $7(2.5)$ & 3 & $0.35 \pm 2.68$ \\
$2015 / 16$ & $8(2.9)$ & 5 & $0.21 \pm 1.96$ \\
$2016 / 17$ & $10(3.7)$ & 1 & $0.46 \pm 3.19$ \\
\hline \multicolumn{4}{c}{ a July - June) } \\
${ }^{b}$ Number of pentads with Starlings (as \% of sampled pentads) \\
${ }^{\mathrm{c}}$ Number of new pentads with Starlings \\
${ }^{\mathrm{d}}$ Reporting rate across all Gauteng pentads (mean \% \pm SD)
\end{tabular}

Table 3: Reporting rate (\%) for Common Starling in Gauteng within pentads containing different land-use types, averaged for all pentads of each type found in the province.

\begin{tabular}{llr}
\hline Land-use & Share of pentad $^{\mathrm{a}}$ & Reporting rate $^{\mathrm{b}}$ \\
\hline Agriculture & $<10$ & 0.1 \\
& $>40$ & 0.3 \\
& $>60$ & 0.0 \\
\hline Natural & $>60$ & 0.1 \\
Settlement & $>60$ & 0.3 \\
Highly transformed & $>10$ & 0.7 \\
\hline aShare of pentad occupied by land-use (\%) & \\
b(\%) &
\end{tabular}

other "aliens" (Rosenzweig 2001; Orchan et al. 2013). This is important to note, as highly transformed environments such as Gauteng contain numerous "alien species" (Symes et al. 2017). As its distribution expands, the Starling may engage in competition for resources with other species in Gauteng, or it may expand to fill a vacant niche (a controversial concept in itself, Lekevicius 2009). If the Common Starling is to follow the footsteps of the Rose-ringed Parakeet Psittacula krameri, an alien species preceding it in Gauteng by a few decades, impacts on "indigenous" birds are predicted to be minimal to insignificant (Ivanova 2017). In attempting to quantify impact, and given that the species is a successful "invader" elsewhere in the world, we suggest that the Common Starling is one to closely monitor.

Public responses to exotic species are often emotive (Gozlan et al. 2013), and may lack credibility altogether when there is either little scientific evidence or when scientific evidence is ignored. From the trends found so far, it is clear that in the South African context much research is still needed to understand the complexities of changing bird communities in the face of rapid anthropogenic change. Indeed the clarification of numerous terms, and the context in which they are applied in this field of research, are frequently inconsistent and need attention (e.g. invasive and alien, as defined by Richardson et al. 2011). Furthermore, this topic needs informed public engagement to help prevent misinformation on complex ecological processes. 
A wealth of information in the form of citizen science SABAP data remains to be mined in helping understand these processes.

\section{Acknowledgements}

We would like to thank the large number of independent observers for their continued contribution to the SABAP2 database, whose work makes possible the project, and our use of it.

\section{References}

Boucher J 2018. eBird Checklist: http:/ / ebird.org/ebird/view/checklist/S16742569 eBird: An online database of bird distribution and abundance [web application]. eBird, Ithaca, New York. Available: http:/ /www.ebird.org. Accessed: 22 January 2018.

Craig AJFK 2005. Common starling Sturnus vulgaris. In: Hockey PAR, Dean WRJ, Ryan PG (eds). Roberts' Birds of Southern Africa, 7th edition. The Trustees of the John Voelcker Bird Book Fund, Cape Town, South Africa: 971-972.

Donald PF, Green RE, Heath MF 2001. Agriculture intensification and the collapse of Europe's farmland bird populations. Proceedings of the Royal Society of London B 268: 25-29.

Ferrer X, Motis A, Peris SJ 1991. Changes in the breeding range of starlings in the Iberian Peninsula during the last 30 years: competition as a limiting factor. Journal of Biogeography 18: 631-636.

Gozlan RE, Burnard D, Andreou D, Britton JR 2013. Understanding the Threats Posed by Non-Native Species: Public vs. Conservation Managers. PLoS ONE 8: e53200.

Ivanova IM 2017. Spatial and temporal impacts of the alien species Psittacula krameri on the occurrence of avifauna in Gauteng. Honours thesis, University of the Witwatersrand, Johannesburg.

Koenig WD 2003. European starlings and their effect on native cavity-nesting birds. Conservation Biology 17: 1134-1140.

Lekevicius E 2009. Vacant niches in nature, ecology, and evolutionary theory: a mini-review. Ekologija 55: 165-174.

Orchan Y, Chiron F, Shwartz A, Kark S 2013. The complex interaction network among multiple invasive bird species in a cavity-nesting community. Biological Invasions 15: 429-445.

Richardson DM, Pysek P, Carlton JT 2011. A compendium of essential concepts and terminology in invasion ecology. In: Richardson DM (ed). Fifty years of invasion ecology: The legacy of Charles Elton. Blackwell Publishing, Oxford, UK: 409-420.

Richardson DM, van Wilgen BW, Higgins SI, Trinder-Smith TH, Cowling RM, McKell DH 1996. Current and future threats to plant biodiversity on the Cape Peninsula, South Africa. Biodiversity and Conservation 5: 607-647.

Rosenzweig ML 2001. The four questions: what does the introduction of exotic species do to diversity? Evolutionary Ecology Research 3: 361-367.

Sauer JR, Hines JE, Fallon J 2008. The North American breeding bird survey, results and analysis 1966-2007. U.S. Geological Survey Patuxent Wildlife Research Centre, Laurel, Maryland. 
Schäffler A, Swilling M 2012. Valuing green infrastructure in an urban environment under pressure - The Johannesburg case. Ecological Economics 86: 246-257.

Symes CT, Roller K, Howes C, Lockwood G, van Rensburg BJ 2017. Grassland to urban forest in 150 years: avifaunal response in an African metropolis. In: Murgui E, Hedbloom M (eds). Ecology and conservation of birds in urban environments. Springer International Publishing, Cham, Switzerland: 309-341.

Van der Merwe F 1984. 'n Nalatenskap van Rhodes: Europese Spreeus verdring Gryskopspegte. African Wildlife 38: 155-157.

Winterbottom JM, Liversidge R 1954. The European starling in the South West Cape. Ostrich 25: 89-96. 